\title{
Interaction study of clay-bearing amphibolite-crude oil-saline water: Molecular level implications for enhanced oil recovery during low saline water flooding
}

\author{
Saheli Sanyal, Kumar Abhishek Singh, Harshil Parekh, \\ Vishrut ChOKShi and UtTAM K Bhui* \\ School of Petroleum Technology, Pandit Deendayal Petroleum University, Raisan, Gandhinagar 382 007, India. \\ ${ }^{*}$ Corresponding author.e-mail: Uttam.bhui@spt.pdpu.ac.in; ukbhui@gmail.com
}

MS received 30 August 2017; revised 7 March 2018; accepted 12 March 2018; published online 29 September 2018

Low saline water flooding (LSWF) had proved to be an efficient method for enhanced oil recovery in clay-bearing hydrocarbon reservoirs, but the interaction mechanisms among in-situ rocks - fluids and injection fluids within the reservoir - are not yet known properly. Understanding the molecular level interaction among these components is critical for designing and field scale implementation of LSWF in clay-bearing crystalline reservoir rocks, which is very limited in the existing literature. A weathered amphibolite rock and one dead crude oil from the Bakrol field (Cambay basin, India) have been used in this study. The presence of clay minerals in the weathered amphibolite rock was observed using a polarising microscope and characterised by the X-ray diffraction (XRD) and Fourier transform infrared (FTIR) techniques. The crude oil and its fractionated SARA components have been extensively studied by spectroscopic techniques for their characterisation. The interaction study among the rock powder, hydrocarbon crude oil and saline water has been performed in the present work for gaining better insight for designing the injection fluid for LSWF. The weathered amphibolite rock powder was mixed with the dead crude oil and kept for 30 days in room temperature $(T)$ and pressure $(P)$ for proper interaction. The XRD, FTIR and cation exchange capacity results clearly demonstrated the incorporation of crude oil components in the interlayer surfaces of clay minerals. The oil removal efficiency, from the oil-treated rock powder of three saline water samples having $\mathrm{NaCl}$ concentration of 3000, 5000 and 8000 ppm, was investigated using the UV-Vis and fluorescence spectroscopies. The low saline $\mathrm{NaCl}$ water is capable of removing the maximum amount of polar components from the oil-treated rock powder. These molecular level insights are valuable for designing effective injection fluid for enhancing the oil recovery from the clay-rich crystalline reservoir rock.

Keywords. Low saline water flooding (LSWF); clay-bearing amphibolite; polycyclic aromatic hydrocarbon (PAH); fused aromatic ring (FAR); UV-Vis spectroscopy; fluorescence spectroscopy.

\section{Introduction}

The petroleum exploration and production industry has ventured out for various innovative techniques to meet the ever increasing demand of energy. Low saline water flooding (LSWF) is one of such techniques which has been extensively employed in the field of enhanced oil recovery (EOR). It has been proved that the presence of clay minerals is one of the key factors for 
successful implementation of the LSWF (Morrow and Buckley 2011; Austad 2013; Sanyal et al. 2017). Clay minerals are sheet silicate or phyllosilicate structures containing mostly aluminium, silicon and small amounts of other elements such as iron, sodium, magnesium, calcium, potassium, etc. (Brindley and Brown 1980). They are generally found as detrital minerals in sandstone (Boles and Franks 1979) reservoirs or they can be formed in sandstone (Worden and Morad 2003), carbonate (Velde and Meunier 2008) and crystalline basement reservoir rocks (Kumar et al. 2002). Most of the studies show that the hydrocarbon reservoir rocks are predominantly rich in kaolinite, smectite, illite and illite-smectite mixed clays (Nasralla et al. 2011; Sheng 2014; Barnaji et al. 2016; Jackson et al. 2016). Kaolinite is a 1:1 layer silicate where one tetrahedral sheet is linked with one octahedral sheet, whereas smectite is a 2:1 layered clay that consists of one octahedral sheet sandwiched between two tetrahedral sheets (Brindley and Brown 1980). The clay minerals possess negative charge because of the substitution of cations either in tetrahedral or in octahedral sites; this charge must be balanced by the presence of an extra positive charge in the form of interlayer cations, situated between the layers (Cosultchi et al. 2005). Petroleum crudes in the hydrocarbon reservoirs comprises four major components: saturates $(\mathrm{S})$, aromatics $(\mathrm{A})$, resins $(\mathrm{R})$ and asphaltenes (As) (Shi et al. 2010). Resins and asphaltenes are polar hydrocarbon components having high affinity towards the clay mineral surfaces and interlayer surfaces (Cosultchi et al. 2005; Underwood et al. 2015; Sanyal et al. 2017). The polar components are adsorbed onto the surface of clay minerals predominantly by van der Waals energy with the smaller contribution of electrostatic energy and H-bonding energy (Murgich and Rodriguez 1998; Underwood et al. 2015).

Based on the laboratory experiments and pilot studies, extensive field scale implementation of LSWF has been carried out in sandstones (Lager et al. 2008; Austad et al. 2010) and carbonate (Zhang and Austad 2006; Yousef et al. 2010; Fathi 2012) reservoir rocks. There are several mechanisms put forward for explaining the incremental oil recovery during the LSWF. These mechanisms are clay particle (fine) migration (Tang and Morrow 1999), osmosis (Morrow and Buckley 2011), increased $\mathrm{pH}$ and reduced interfacial tension similar to the alkaline flooding (Mcguire et al. 2005), multi-component ion exchange (Lager et al. 2008; Ligthelm et al. 2009; Lee et al. 2010; Nasralla et al. 2011), expansion of the double layer (Ligthelm et al. 2009; Nasralla and Nasr-El-Din 2014; Xie et al. 2014), mineral dissolution ( $\mathrm{Pu}$ et al. 2010), salting-in effect (Rezaeidoust et al. 2009) and salting-out effect (Lashkarbolooki et al. 2016). However, the molecular level interaction between the clay types and the polar components of crude oil present in the hydrocarbon reservoir is still not clear. Moreover, the suitable salinity range and preferable cations in the injection water for enhancing oil recovery from the clay laden hydrocarbon reservoirs are still controversial.

Thus, understanding these molecular level interactions is the primary requirement for designing the low saline water for EOR. Different spectroscopic techniques (Fourier transform infrared (FTIR) spectroscopy, UV-Vis absorption spectroscopy, fluorescence spectroscopy, etc.) have been used over the last few decades for the chemical characterisation of crude oil components (Ryder 2005; Zhao et al. 2006; Yoon et al. 2009; Pantoja et al. 2011; Meléndez et al. 2012). However, the use of spectroscopic techniques particularly to understand the molecular level interaction among rock powder, crude oil and injection saline water and thereby designing the effective injection saline water for enhancing the oil recovery is very limited in the literature (Fogden 2012; Katika et al. 2016; Sanyal et al. 2017). In the present work, an attempt has been made to understand the molecular level interaction among clay-bearing amphibolite powder, crude oil and saline water for designing the injection water for effective LSWF. Spectroscopic techniques particularly, FTIR spectroscopy, UV-Vis absorption spectroscopy and fluorescence spectroscopy were used for understanding the interaction behaviour. We established that the composition of the clay minerals and the type of crude oil present within the reservoir rock are the key guiding factors for designing the effective injection fluid during the LSWF for oil recovery.

\section{Experimental section}

\subsection{Materials}

A wide exposure of the weathered amphibolite rock was selected for sample collection. It appeared from the exposure that some portion of the rock preserved its original metamorphic texture whereas in some parts they were weathered variably with 
Table 1. ${ }^{\circ} A P I$ and weight percentage (wt\%) of each SARA fractions of the used crude oil (S1).

\begin{tabular}{lcccccc}
\hline & & \multicolumn{5}{c}{ SARA components } \\
\cline { 3 - 7 } & API & $\begin{array}{c}\text { Saturates } \\
(\%)\end{array}$ & $\begin{array}{c}\text { Aromatics } \\
(\%)\end{array}$ & $\begin{array}{c}\text { Resins } \\
(\%)\end{array}$ & $\begin{array}{c}\text { Asphaltenes } \\
(\%)\end{array}$ & $\begin{array}{c}\text { Total } \\
(\%)\end{array}$ \\
\hline S1 & 32.08 & 48 & 25 & 12.06 & 10 & 95.06 \\
\hline
\end{tabular}

the formation of clay minerals. Representative thin sections were prepared for the identification of minerals and their textural attributes from the visually appeared pristine and weathered amphibolite rock samples. However, the present work is performed with the weathered rock sample (WA1). The weathered rock sample was crushed and sieved for the analysis and characterisation. The powder sample of the rock was oven dried at $90^{\circ} \mathrm{C}$ and characterised using X-ray diffraction (XRD) and FTIR spectroscopy analyses. The cation exchange capacity (CEC) value for the rock powder was also measured.

The dead crude oil, designated as S1, from the Bakrol field of Cambay basin was provided by Selan Exploration Technology Ltd. and was used in this study. The asphaltene fractions from the S1 crude oil has been separated using ASTM D2007-80, where $2 \mathrm{ml}$ of crude oil was added into $80 \mathrm{ml}$ of $\mathrm{n}$ pentane followed by stirring and then the mixture was equilibrated for 2 days at ambient conditions. The flask containing the mixture was shaken at least twice a day during the equilibration time. The solid asphaltenes were separated using $0.45 \mu \mathrm{m}$ filter paper and dried. After removal of residual npentane, the solid asphaltenes were weighted. The filtered-out sample (maltane fraction) was later split in a chromatographic column packed with a silica gel (prepared by mixing of $60 \mathrm{~g}$ silica gel in n-hexane). Saturates, aromatics and resins fractions were eluted from the column with the use of n-hexane, toluene, and mixture of methanol and dichloromethane (1:1) respectively. The solvents used were extracted using the Soxhlet apparatus and the percentage of each fraction was calculated. The ${ }^{\circ} \mathrm{API}$ value and weight percentage of the saturates (S), aromatics (A), resins $(\mathrm{R})$ and asphaltenes (A), i.e., SARA fractions of the $\mathrm{S} 1$ crude oil are given in table 1 . The UV-Vis absorbance and steady-state emission spectra of the bulk crude oil and individual components of SARA fractions were captured for detailed crude oil characterisation.

Sodium chloride ( $\mathrm{NaCl}$, Merck, $99 \%$ purity) was used to prepare the saline water of 3000,5000 and 8000 ppm concentration.

\subsection{Sample preparation and experimentation}

The rock powder (WA1) was properly mixed with sufficient amount of the study crude oil (S1) and kept in the hot oven (drying oven) for 30 days for interaction between the two. The oil-treated rock powder was washed with n-hexane repeatedly, followed by de-ionised water to ensure the complete removal of excess surficial oil. The washed rock powder was oven dried and kept in an air-tight bottle for characterisation using the FTIR spectroscopy and measuring CEC.

One gram of oil-treated dried rock powder was taken in each of three $50 \mathrm{ml}$ graduated cylinders. $\mathrm{NaCl}$ solutions of 3000,5000 and 8000 ppm were added up to $25 \mathrm{ml}$ mark in every cylinder and were shaken vigorously followed by settling of the same for next $24 \mathrm{hr}$. The solid and liquid phases were separated with the help of filtration with $0.45 \mu \mathrm{m}$ size filter paper. The separated liquid phase was collected in the liquid sampler.

\subsection{Instrumentation}

\subsubsection{X-ray diffraction}

The XRD analysis of dry rock powder (WA1) and oil-treated rock powder (WA1S1) was performed with the PANalytical X-ray powder diffractometer with Ni-filtered $\mathrm{CuK} \alpha$ radiation employing a range of $4^{\circ}-60^{\circ}$ at a step size of $0.05^{\circ} / 2 \theta$ and a count time of $1.5 \mathrm{~s}$ per step. The mineral identification was done with the standard $2 \theta$ value from the established literature. The semi-quantitative mineral percentage $(\%)$ was calculated using the peak height and presented in figure 1.

\subsubsection{FTIR spectroscopy}

Both untreated (WA1) and oil-treated (WA1S1) powder samples were combined separately with the spectroscopic grade $\mathrm{KBr}$ (1:20) in an agate mortar and pressed by a handheld KBr press machine for making pellets. The FTIR spectra (untreated i.e., WA1 and oil treated, i.e., WA1S1) were acquired 
by PerkinElmer FTIR spectrometer (Spectrum Two model) version 10.4.2 using the $\mathrm{KBr}$ pellet technique. The FTIR spectrum of S1 was recorded with the same instrument using the attenuated total reflectance (ATR) mode. The ATR cell was equipped with a diamond crystal having a refractive index of 2.4. The transmittance spectra were captured by taking average of 20 scans with the

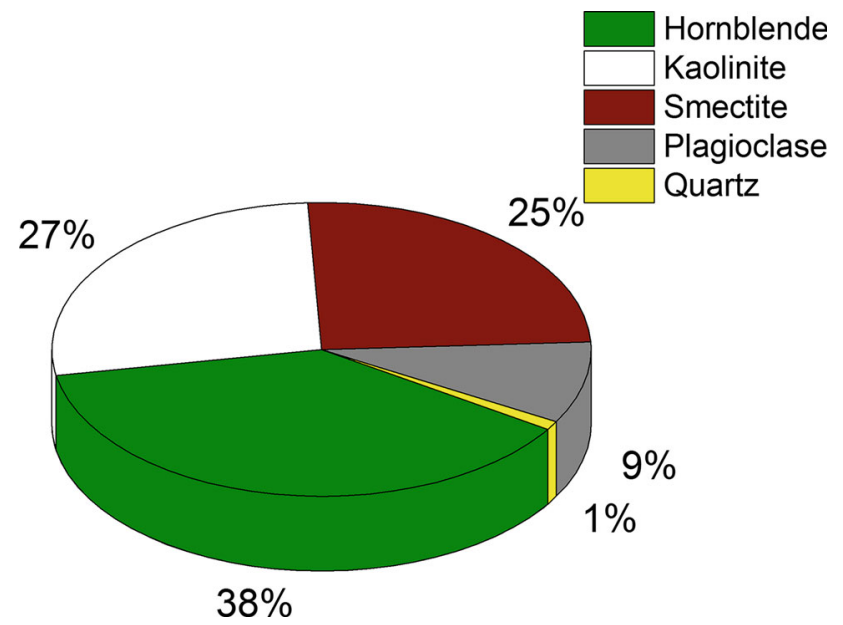

Figure 1. Pi diagram of XRD calculated abundances of minerals or mineral classes for bulk rock (WA1). wavenumber range of $4000-400 \mathrm{~cm}^{-1}$ at room temperature.

\subsubsection{Cation exchange capacity}

The CEC of untreated and oil-treated WA1 samples were determined according to the ASTM C 837-81 (the standard test method for methylene blue index of clay).

\subsubsection{UV-Vis spectroscopy}

Absorption spectra of solvent separated SARA fractions (diluted in toluene at 1:1000 ratio) from the dead crude oil sample (S1) and the filtered saline water samples prepared from the oil-treated WA1 were recorded using the PerkinElmer Lambda 35 spectrometer employing 200-800 nm wavelength range. Optical quartz cuvettes $\left(10 \mathrm{~mm}^{2}\right)$ were used to hold the sample and reference (toluene for SARA fractions and neat saline water solutions for filtered saline water samples) solutions.

\subsubsection{Fluorescence spectroscopy}

The steady-state fluorescence spectra of SARA fractions (diluted in toluene at 1:1000) and

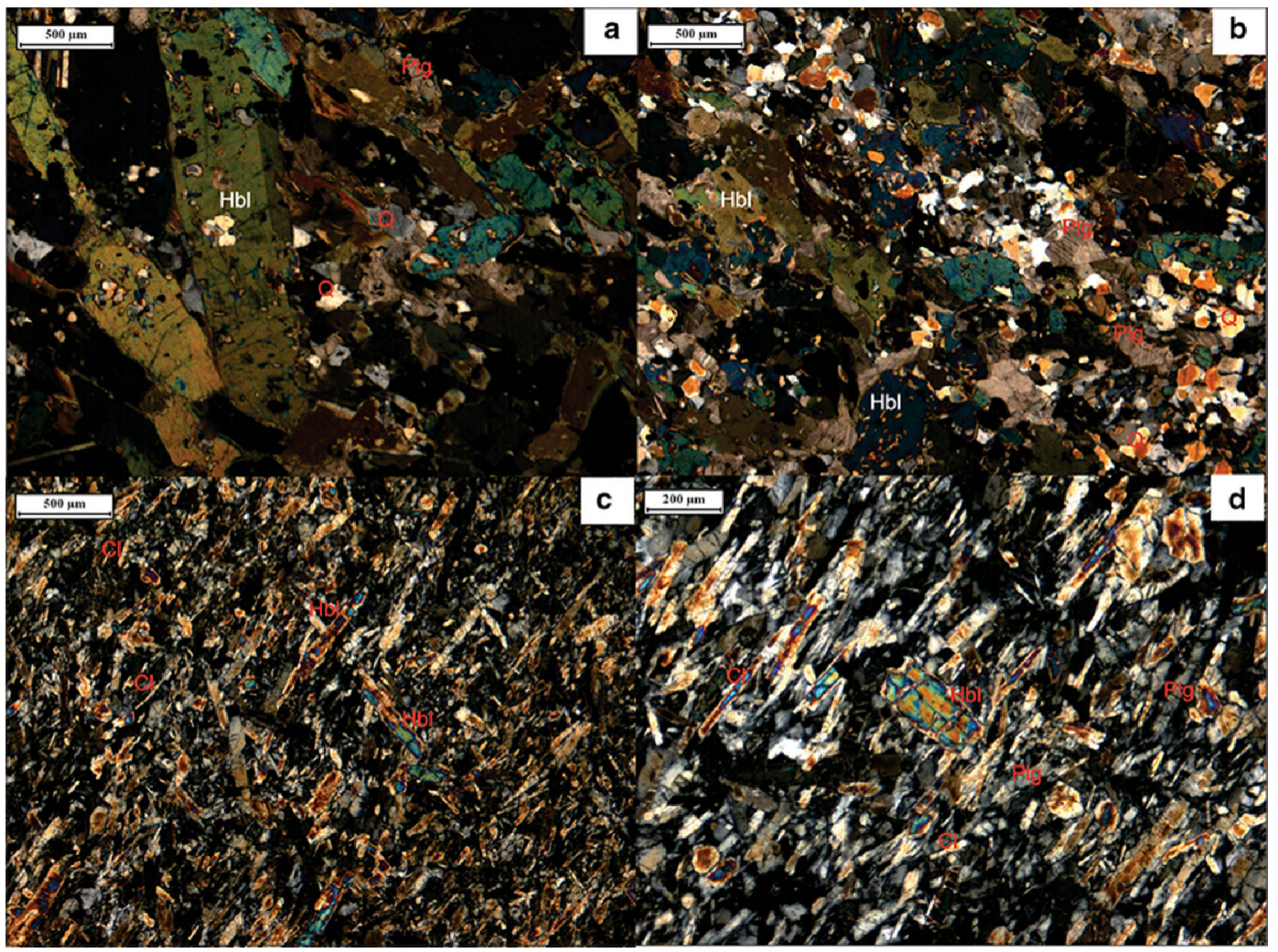

Figure 2. Photomicrograph of (a and $\mathbf{b})$ pristine amphibolite and (c and $\mathbf{d}$ ) weathered amphibolite under the X-polarised light. The weathered amphibolite is showing a change in mineralogy, textural pattern and grain size reduction. Hbl: hornblende; Pl: plagioclase; Q: quartz; Cl: clay minerals. 
filtered saline water samples were measured over a wavelength range of $200-700 \mathrm{~nm}$ on a PerkinElmer LS55 fluorescence spectrophotometer. The excitation and emission slit width was kept at $5 / 5 \mathrm{~nm}$ and the scanning speed was $500 \mathrm{~nm} / \mathrm{min}$ for recording the spectra. Emission spectra of all the filtered saline water solutions were also recorded at 300 excitation wavelength.

\section{Results and discussion}

\subsection{Rock characterisation}

\subsubsection{Polarising microscope}

The microscopic observation of the megascopically pristine amphibolite sample clearly demonstrated that it consisted mainly of hornblende and plagioclase, with a little amount of quartz and showing typical intergranular texture (figure 2a and b). However, the weathered amphibolite WA1 is showing an extensive development of clay minerals at the expense of hornblende and plagioclase which is confirmed by the modal mineralogy as well as textural change. The hornblende and plagioclase grains are highly fractured and altered to clay minerals with the reduction in grain size (figure $2 \mathrm{c}$ and $\mathrm{d}$ ). The texture of WA1 is completely altered and showing little grain alignment defined by numerous needle-shaped grains (figure $2 \mathrm{c}$ and $\mathrm{d}$ ).

\subsubsection{X-ray diffraction}

The XRD pattern of the rock powder (WA1) is presented in figure 3 with the characteristic $d$ space values and the symbols of the minerals against each respective peak. The XRD pattern

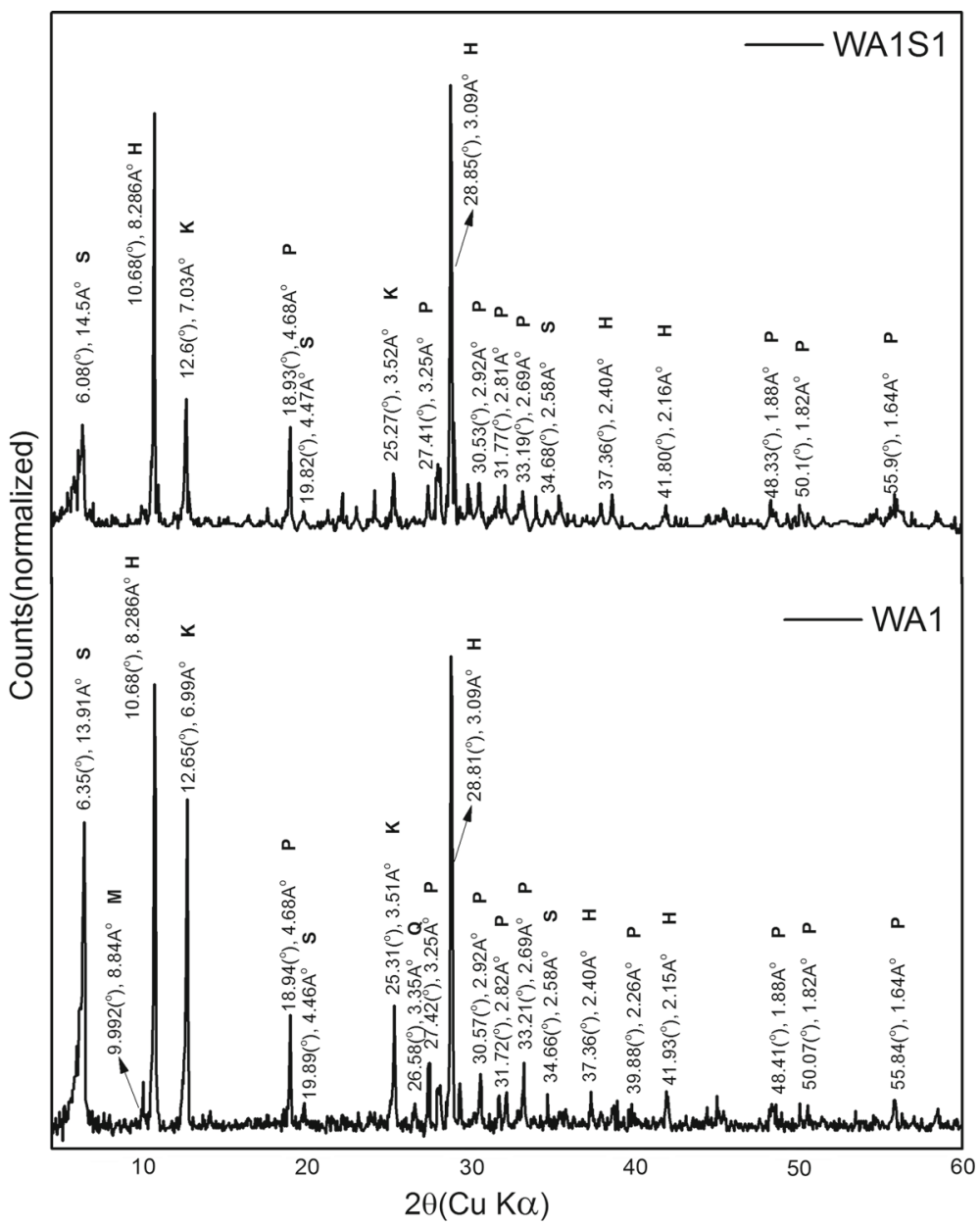

Figure 3. XRD pattern of untreated weathered amphibolite (WA1) rock powder and crude oil-treated weathered amphibolite (WA1S1) powder. The mineral symbols along with their specific $2 \theta$ and $d$-space values are assigned for the corresponding peaks. The assignments of the minerals are as follows. S: smectite; H: hornblende; K: kaolinite; P: plagioclase; Q: quartz; M: muscovite. 
revealed that the rock consists of hornblende and plagioclase with clay minerals, particularly kaolinite and smectite (Proust et al. 2006; Ozgen and Yildiz 2010; Worasith et al. 2011). The quantitative mineralogy percentage (\%) of WA1 is given in figure 1 using the standard procedure of peak heights from the XRD results.

\subsubsection{FTIR spectroscopy}

The FTIR transmission spectrum of WA1 rock powder with characteristic transmission bands is presented in figure 4. It reveals the presence of bands at 3695, 3620, 3564 and $3384 \mathrm{~cm}^{-1}$ representing the $\mathrm{O}-\mathrm{H}$ stretching vibration and $1633 \mathrm{~cm}^{-1}$ for the $\mathrm{H}-\mathrm{O}-\mathrm{H}$ deformation. The peak appeared at $998 \mathrm{~cm}^{-1}$ is assigned for $\mathrm{SiO}_{2}$ stretching vibration. The peak at $752 \mathrm{~cm}^{-1}$ is indicating the $\mathrm{Si}-\mathrm{O}-\mathrm{Al}$ compound vibration. The peak at $686 \mathrm{~cm}^{-1}$ presents the $\mathrm{SiO}$ in quartz, and 642 and $528 \mathrm{~cm}^{-1}$ are associated with the $\mathrm{Si}-\mathrm{O}-\mathrm{Si}$ bending. The peak at $429 \mathrm{~cm}^{-1}$ presents the $\mathrm{Si}-\mathrm{O}-\mathrm{Si}$ bending (Tyagi et al. 2006; Saikia and Parthasarathy 2010; Worasith et al. 2011; Ikhtiyarova et al. 2012).

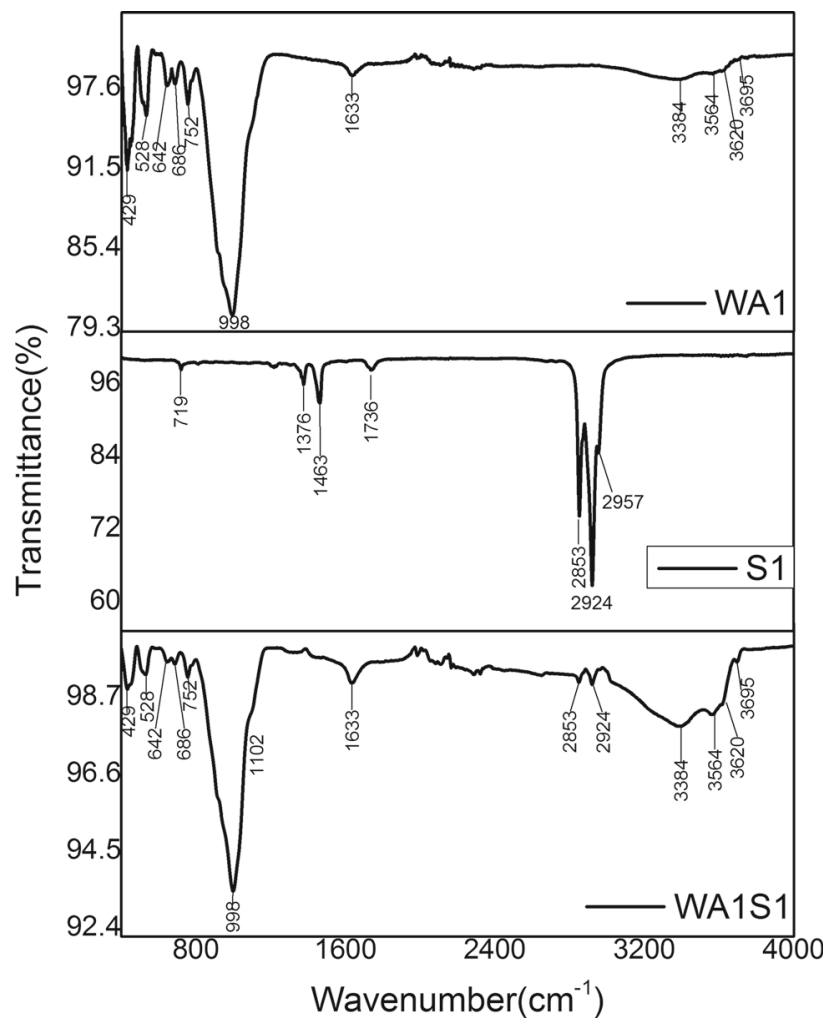

Figure 4. FTIR spectra of untreated WA1, neat crude oil (S1) and oil-treated rock powder (WA1S1) samples. The oiltreated WA1 samples exhibit the presence of new sets of bands at 2924 and $2853 \mathrm{~cm}^{-1}$.

\subsubsection{Cation exchange capacity}

The measured CEC value of the rock powder WA1 is $6.8 \mathrm{meq} / 100 \mathrm{~g}$.

\subsection{Crude oil characterisation}

\subsubsection{FTIR spectroscopy}

The FTIR spectra of S1 crude oil (figure 4) is showing characteristic functional groups in three distinct regions: (i) in the high-frequency region (3100-2800 $\mathrm{cm}^{-1}$ ) due to the presence of $\mathrm{C}-\mathrm{H}$ stretching vibrations, (ii) in the medium-frequency region $\left(1700-1000 \mathrm{~cm}^{-1}\right)$ as a result of $\mathrm{C}-\mathrm{C}$ stretching of aromatic structures and aliphatic $\mathrm{C}-\mathrm{H}$ bending, and (iii) in the low-frequency region (1000-600 $\left.\mathrm{cm}^{-1}\right)$ due to characteristic bands of the aromatic $\mathrm{C}-\mathrm{H}$ out-of-plane bending modes (Gargiulo et al. 2015; Merola et al. 2016).

\subsubsection{UV-Vis spectroscopy}

The UV-Vis spectra of S1 crude oil and its SARA fractions were presented in figure 5. Yoon et al. (2009) reported that the onset wavelength of the absorption peak of the polycyclic aromatic hydrocarbon (PAH) of two fused aromatic ring (FAR), 3FAR, and 4FAR exists near 200-220, 250-257 and 278-338 nm, respectively. It has been found (figure 5) that all the spectra show major absorption bands in the range of $270-550 \mathrm{~nm}$ indicating the presence of $3 \mathrm{FAR}$ or $4 \mathrm{FAR}$ in the oil components. The spectrum of asphaltene is showing higher absorbance values in the visible wavelength suggesting the presence of high molecular weight aromatic moieties in it. The presence of characteristic metal porphyrins is registered in asphaltene structure by a small hump near $402 \mathrm{~nm}$ (Evdokimov et al. 2003) which is not exhibited by other oil fractions. The crude oil (S1) spectrum almost mimic the spectrum of aromatics (A) fraction; however, at wavelength $400 \mathrm{~nm}$ the $\mathrm{S} 1$ spectrum exhibits a hump which is due to the metal porphyrin present in asphaltenes.

\subsubsection{Fluorescence spectroscopy}

The steady-state emission spectra of S1 crude oil and its SARA fractions are presented in figure 6 . The saturate fraction exhibits a very less flat-type emission with very low fluorescence intensity compared to the other fractionsof crude oil 


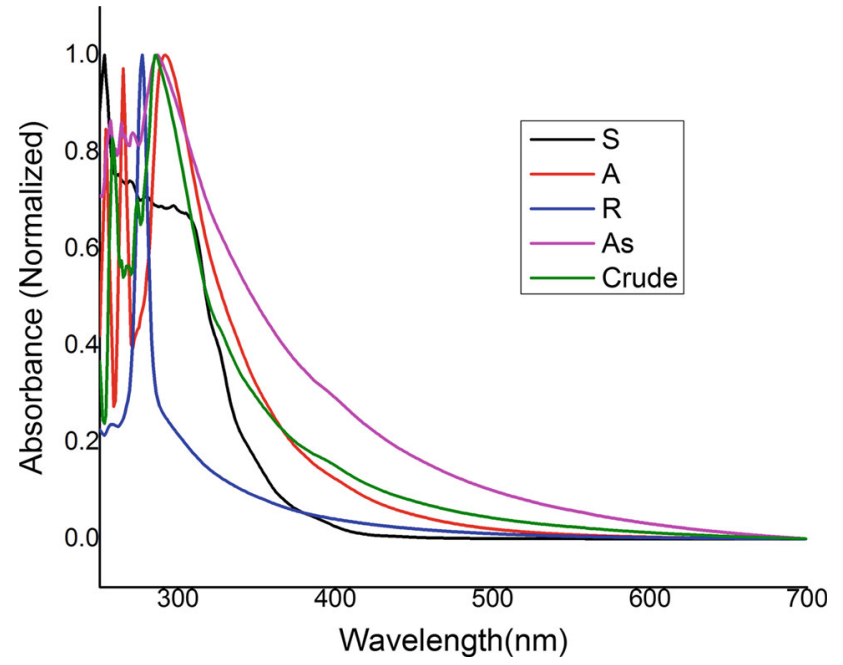

Figure 5. UV-Vis spectra of S1 crude oil and its separated components, saturates $(\mathrm{S})$, aromatics $(\mathrm{A})$, resin $(\mathrm{R})$ and asphaltene (As).

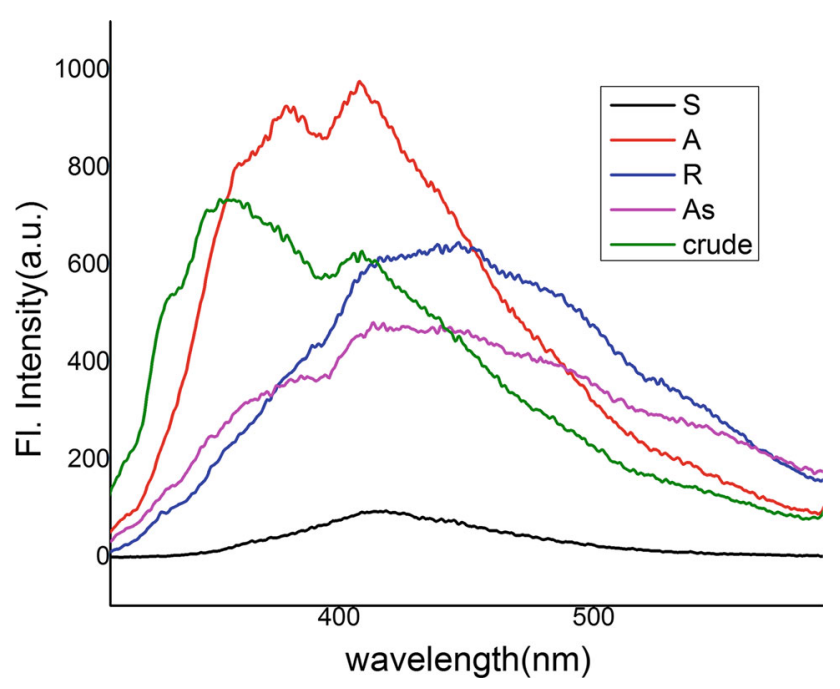

Figure 6. Fluorescence emission spectra of S1 crude oil and its saturates $(\mathrm{S})$, aromatics $(\mathrm{A})$, resins $(\mathrm{R})$ and asphaltenes $($ As) at $300 \mathrm{~nm}$ excitation wavelength $(\lambda$ exc).

(Lambert et al. 2003). The aromatic fraction shows a sharp intense spectrum indicating the presence of fused ring PAH compounds. The emission spectra exhibited by resins and asphaltenes are broad and showing red shift compared to aromatic fractions proving the presence of high molecular weight three to six PAH structures and their aggregation (Pantoja et al. 2011). The shape of the emission spectrum of the crude oil is very similar to the emission spectrum of the aromatic fractions suggesting that the aromatics are the major emitting phase in the crude oil (Pantoja et al. 2011).

\subsection{Oil-treated rock powder characterisation}

\subsubsection{X-ray diffraction}

The XRD peaks of WA1 and oil treated (WA1S1) are presented in figure 3 to determine the variation after oil treatment. It has been found that the $d$-space values of the clay minerals (smectites and kaolinites) are increased (from 13.91 to $14.5 \AA$ for smectite and 6.99 to $7.03 \AA$ for kaolinite) which may be due to the adsorption of organic components of crude oils onto the interlayer surface of the clay minerals (Lagaly et al. 2006; Liu et al. 2013). Moreover, the peak intensity is also decreased after the oil interaction which further underpins the oil adsorption onto the interlayer surfaces (Sugahara et al. 1990).

\subsubsection{FTIR spectroscopy}

The FTIR spectrum of the oil-treated WA1 sample (given in figure 4) shows the presence of the new set of bands at 2924 and $2853 \mathrm{~cm}^{-1}$ which are absent in the untreated WA1. The bands at 2954 and $2853 \mathrm{~cm}^{-1}$ are attributed to the $\mathrm{C}-\mathrm{H}$ antisymmetric and symmetric stretching in an aliphatic hydrocarbon. The appearance of these bands in the oil-treated WA1 spectrum suggests the adsorption of crude oil components onto the outer surfaces and interlayer surfaces (Adams 2014; Underwood et al. 2015) of smectite clay. The FTIR spectrum of oil-treated sample reveals that the polar crude oil components are adsorbed onto the clay layer surfaces and are rich in primary aliphatic chains (Pernyeszi et al. 1998).

\subsubsection{Cation exchange capacity}

The CEC value of the rock powder after the oil treatment is reduced to $4.5 \mathrm{meq} / 100 \mathrm{~g}$. The reduction of the CEC value of the oil-treated WA1 sample after the oil treatment can be explained as a result of the adsorption of polar crude oil components onto the surfaces of clay present in WA1 (Clementz 1982; Dean et al. 1986).

\subsection{Filtered-out saline water characterisation}

\subsubsection{UV-Vis spectroscopy}

The UV-Vis absorption spectra show prominent three peaks at 222, 268 and $323 \mathrm{~nm}$ (given in figure $7 \mathrm{a}$ ) suggesting the incorporation of small as 

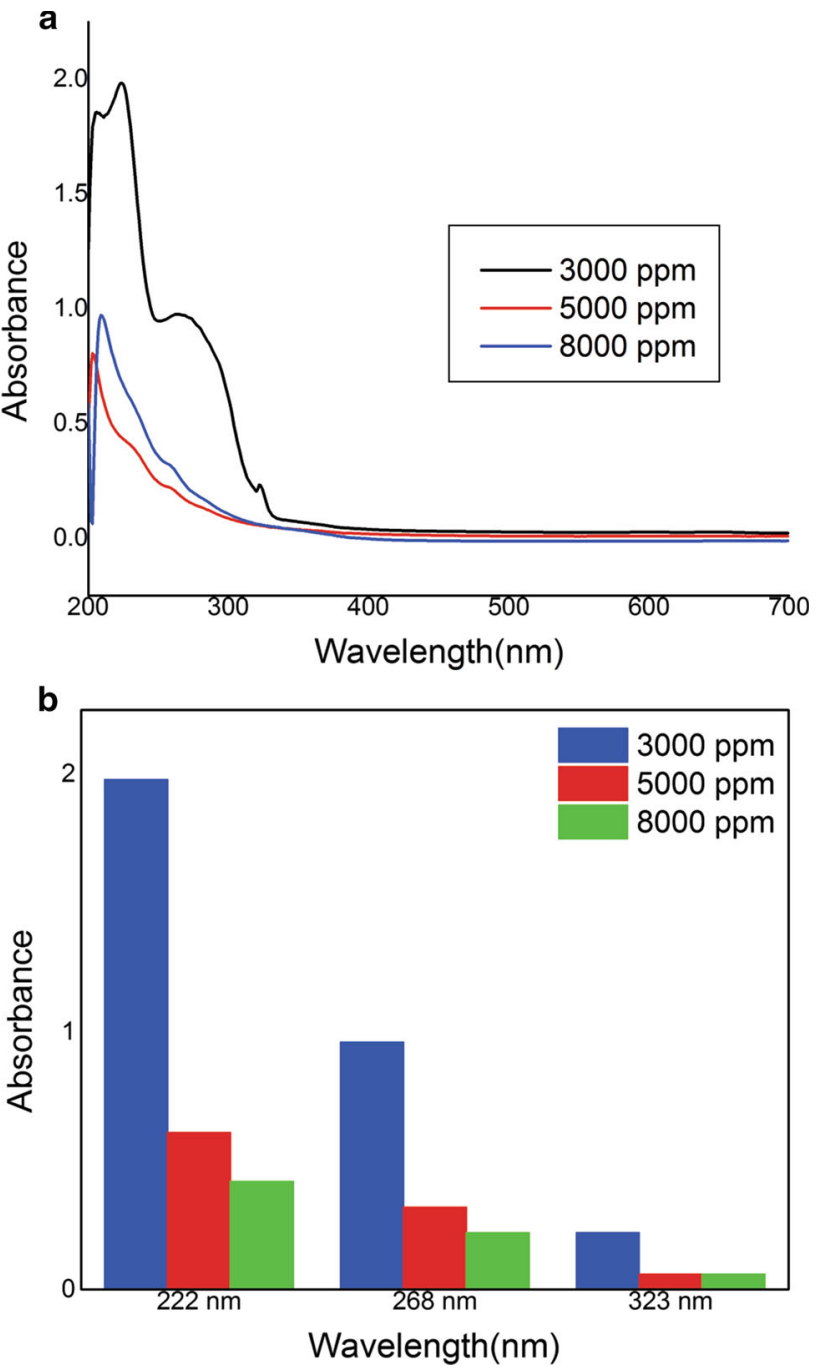

Figure 7. (a) The absorption spectra for saline waters (3000, 5000 and $8000 \mathrm{ppm}$ ) after interaction with the oil-treated WA1. (b) Column plot of absorbance value showing by the filtered saline water of 3000, 5000 and $8000 \mathrm{ppm}$. The column plot is drawn based on the absorption peaks at 222, 268 and $323 \mathrm{~nm}$.

well as large FAR rings inside the saline water samples. In figure 7(b), the column plot depicts the absorbance values for three different saline water samples at wavelength values of 222, 268 and $323 \mathrm{~nm}$. It has been found that $3000 \mathrm{ppm}$ filtered saline water sample $(\mathrm{NaCl}$ solution after interacting with oil-treated WA1) is showing the high absorbance values compared to 5000 and $8000 \mathrm{ppm}$, manifesting the presence of a large amount of different aromatic components with 2 FAR-4FAR structures in the saline water. Thus, $3000 \mathrm{ppm}$ has higher potential for oil removal from the oil-treated WA1 sample than the rest two saline water samples (5000 and $8000 \mathrm{ppm})$.

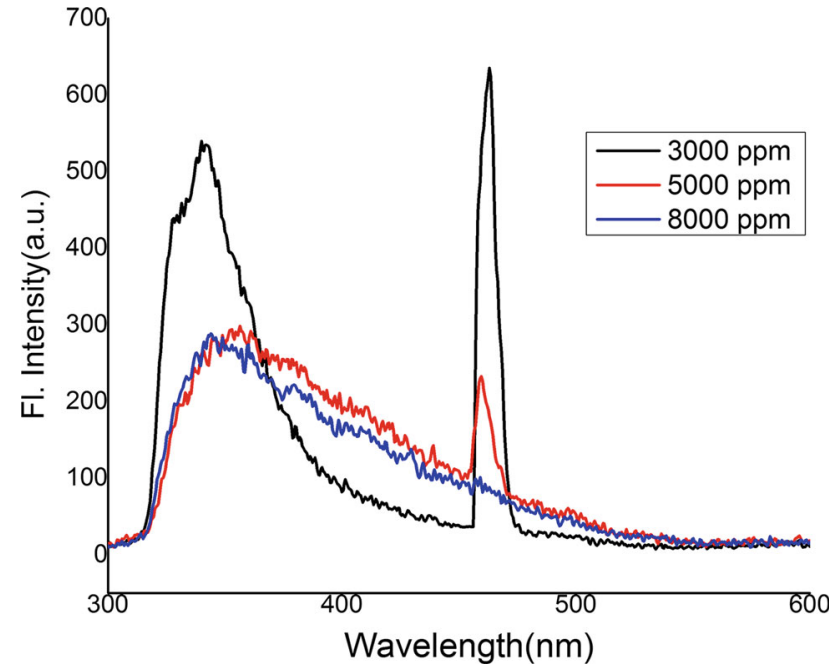

Figure 8. The fluorescence emission spectra for filtered saline waters (3000, 5000 and 8000 ppm) after interaction with the oil-treated WA1.

\subsubsection{Fluorescence spectroscopy}

The inference drawn from the UV-Vis spectra can be further supported by the fluorescence emission spectra (given in figure 8) where the low saline water $(3000 \mathrm{ppm})$ is showing high fluorescence intensity with respect to 5000 and 8000 ppm saline water. This again suggests the oil removal efficiency of $3000 \mathrm{ppm}$ saline from oil-treated rock powder over the rest saline water samples. Moreover, the spectra are showing an almost similar type of emission pattern extending from 320 to $455 \mathrm{~nm}$ range which implied the presence of different aromatic moieties, i.e., PAH containing three to five FAR of various sizes within the saline water samples (Groenzin and Mullins 2000). The recorded emission spectra demonstrated that the saline water samples are able to remove the polar oil components rich in three to five FAR from the oil adsorbed clay minerals (Kasha 1960; Merola et al. 2016).

Hence, a weathered basement reservoir rock, where the kaolinite and smectite clay minerals are predominating, low saline water (3000 ppm) rich in $\mathrm{Na}^{+}$cation would help to increase the oil recovery by removing the polar oil components rich in three to five FAR from the clay layer surface.

\section{Conclusions}

The present study demonstrates the detailed molecular level interaction behaviourof clay-rich 
amphibolite (WA1) with dead crude oil (S1) followed by an extensive discussion on the effectiveness of saline water (3000, 5000 and $8000 \mathrm{ppm})$ for oil removal from the oil-treated WA1.

The WA1 is rich in smectite and kaolinite and $\mathrm{S} 1$ is a medium gravity $\left(32.08^{\circ} \mathrm{API}\right)$ crude oil containing $22 \mathrm{wt} \%$ polar components (resins and asphaltenes). These resin and asphaltenes are rich with heavy molecular weight aromatic moieties having three to six FAR structures. These polar crude oil components are adsorbed onto the clay surfaces present in the WA1 as evident from the XRD, FTIR and CEC analyses. The low saline water $(\mathrm{NaCl})$ particularly of $3000 \mathrm{ppm}$ is showing the signatures of maximum removal of polar oil components rich in three to five FAR from the oil-treated rock powder. These molecular level insights by the spectroscopic methods are helpful for designing the customised EOR fluid during LSWF. Further study with different cations of variable concentration level with the different combination of crude oils and clay minerals may provide a generalised view for designing the injection saline water for optimised recovery from the clay laden crystalline reservoirs.

\section{Acknowledgements}

SS thanks Pandit Deendayal Petroleum University (PDPU) for her research fellowship. The Reservoir Characterization Laboratory (RCL for UV-Vis and Fluorescence data) and the Petroleum Engineering Laboratory (for sample preparation and experimentation) of the School of Petroleum Technology, PDPU, are greatly acknowledged. The authors acknowledge the support of the Solar Research Development Centre (SRDC) and the Chemistry Laboratory of PDPU for providing the XRD and FTIR data support. The authors would like to thank Selan Exploration Technology Ltd. for providing the crude oil used in this research. The authors thank Mr. Bhavesh Mehta for his support and assistance during the laboratory work.

\section{References}

Adams J J 2014 Asphaltene adsorption, a literature review; Energy Fuels 28 2831-2856.

Austad T 2013 Enhanced Oil Recovery Field Case Studies; Elsevier.

Austad T, Rezaeidoust A and Puntervold T 2010 Chemical mechanism of low salinity water flooding in sandstone reservoirs; In: SPE Improved Oil Recovery Symposium, Society of Petroleum Engineers, Aberdeen, Scotland, pp. $1-18$.

Barnaji M J, Pourafshary P and Rasaie M R 2016 Visual investigation of the effects of clay minerals on enhancement of oil recovery by low salinity water flooding; Fuel 184 826-835.

Boles J R and Franks S G 1979 Clay diagenesis in Wilcox sandstones of southwest Texas: Implications of Smectite diagenesis on sandstone cementation; J. Sediment. Res. 49 55-70.

Brindley G and Brown G 1980 Crystal Structures of Clay Minerals and Their Identification; Mineralogical Society, London, 5.

Clementz D 1982 Alteration of Rock Properties by Adsorption of Petroleum Heavy Ends: Implications for Enhanced Oil Recovery; Society of Petroleum Engineers, USA.

Cosultchi A, Cordova I, Valenzuela M A, Acosta D R, Bosch $\mathrm{P}$ and Lara V H 2005 Adsorption of crude oil on $\mathrm{Na}^{+}$Montmorillonite; Energy Fuels 105 1417-1424.

Dean K, James L and McAtee J 1986 Asphaltene adsorption on clay; Appl. Clay Sci. 1 313-319.

Evdokimov I N, Eliseev N Y and Akhmetov B R 2003 Assembly of asphaltene molecular aggregates as studied by near-UV/visible spectroscopy I. Structure of the absorbance spectrum; J. Pet. Sci. Eng. 37 135-143.

Fathi S J 2012 Water-based enhanced oil recovery (EOR) by 'Smart Water' in carbonate reservoirs; In: Proceedings of the SPE EOR Conference at Oil and Gas, West Asia.

Fogden A 2012 Removal of crude oil from kaolinite by water flushing at varying salinity and pH; Colloids Surf. A 402 $13-23$.

Gargiulo V, Apicella B, Alfè M, Russo C, Stanzione F, Tregrossi A and Ciajolo A 2015 Structural characterization of large polycyclic aromatic hydrocarbons. Part 1: The case of coal Tar pitch and Naphthalene-derived pitch; Energy Fuels 29 5714-5722.

Groenzin H and Mullins O C 2000 Molecular size and structure of asphaltenes from various sources; Energy Fuels $\mathbf{1 4}$ 677-684.

Ikhtiyarova G A, Ozcan A S, Gok O and Ozcan A 2012 Characterization of natural- and organo-bentonite by XRD, SEM, FT-IR and thermal analysis techniques and its adsorption behaviour in aqueous solutions; Clay Miner. 47 31-44.

Jackson M D, Vinogradov J, Hamon G and Chamerois M 2016 Evidence, mechanisms and improved understanding of controlled salinity waterflooding part 1: Sandstones; Fuel $185772-793$.

Kasha M 1960 Paths of molecular excitation; In: Proceedings of a Symposium Sponsored by the US Atomic Energy Commission, New York.

Katika K, Ahkami M, Fosbøl P L, Halim A Y, Shapiro A, Thomsen K and Fabricius I L 2016 Comparative analysis of experimental methods for quantification of small amounts of oil in water; J. Pet. Sci. Eng. 147 459-467.

Kumar A, Pendkar N and Sangeeta 2002 Delineation and evaluation of basaltic Deccan basement reservoir of Padra field, Cambay Basin, India - A field study; In: SPWLA 43rd Annual Logging Symposium.

Lagaly G, Ogawa M and Dekany I 2006 Clay mineral organic interactions; In: Handbook of Clay Science (eds) Bergaya 
F, Theng B K G and Lagaly G, Amsterdam, Elsevier 1 309-377.

Lager A, Webb K J, Black C J J, Singleton M and Sorbie K S 2008 Low salinity oil recovery - An experimental investigation; Petrophysics 49 28-35.

Lambert P, Goldthorp M, Fieldhouse B, Wang Z, Fingas M, Pearson L and Collazzi E 2003 Field fluorometers as dispersed oil-in-water monitors; J. Hazard. Mater. 102 57-79.

Lashkarbolooki M, Riazi M, Hajibagheri F and Ayatollahi S 2016 Low salinity injection into asphaltenic-carbonate oil reservoir, mechanistical study; J. Mol. Liq. 216 377-386.

Lee S Y, Webb K J, Collins I R, Lager A, Clarke S M, Sullivan M O and Wang X 2010 Low salinity oil recovery Increasing understanding of the underlying mechanisms; In: SPE Improved Oil Recovery Symposium.

Ligthelm D J, Gronsveld J, Hofman J P, Brussee N J, Marcelis F and van der Linde H A 2009 Novel waterflooding strategy by manipulation of injection brine composition; In: SPE EUROPEC/EAGE Annual Conference and Exhibition.

Liu H, Yuan P, Quin Z, Tan D, Zhu J and He H 2013 Thermal degradation of organic matter in the interlayer clay - Organic complex: A TG-FTIR study on a montmorillonite/12-aminoluric acid system; Appl. Clay Sci. 80-81 398-406.

Mcguire P L L, Chatham J R R, Paskvan F K K, Sommer D M M and Carini F H 2005 Low salinity oil recovery: An exciting new EOR opportunity for Alaska's north slope; In: SPE Western Regional Meeting.

Meléndez L V, Adriana L, Orrego-Ruiz J A, Pachón Z and Mejía-Ospino E 2012 Prediction of the SARA analysis of Colombian crude oils using ATR-FTIR spectroscopy and chemometric methods; J. Pet. Sci. Eng. 90-91 56-60.

Merola M C, Carotenuto C, Gargiulo V, Stanzione F, Ciajolo A and Minale M 2016 Chemical-physical analysis of rheologically different samples of a heavy crude oil; Fuel Process. Technol. 148 236-247.

Morrow N and Buckley J 2011 Improved oil recovery by low-salinity waterflooding; J. Petrol. Tech. 63 106112.

Murgich J and Rodriguez J M 1998 Interatomic interactions in the adsorption of asphaltenes and resins on kaolinite calculated by molecular dynamics; Energy Fuels 12 339343.

Nasralla R A and Nasr-El-Din H A 2014 Double-Layer Expansion: Is it a Primary Mechanism of Improved Oil Recovery by Low-Salinity Waterflooding?; SPE Reservoir Evaluation \& Engineering, USA.

Nasralla R A, Alotaibi M B and Nasr-El-Din H A 2011 Efficiency of oil recovery by low salinity water flooding in sandstone reservoirs; In: SPE Western North American Region Meeting.

Ozgen S and Yildiz A 2010 Application of Box-Behnken design to modeling the effect of Smectite content on swelling to hydrocyclone processing of bentonites with various geologic properties; Clays Clay Miner. 58 431448.

Pantoja P A, Juan L, Le Roux G A, Quina F H and Nascimento C A 2011 Prediction of crude oil properties and chemical composition by means of steady-state and timeresolved fluorescence; Energy Fuels 25 3598-3604.

Pernyeszi T, Patzkó A, Berkesi O and Dékány I 1998 Asphaltene adsortion on clays and crude oil reservoir rocks; Colloids Surf. A 173 373-384.

Proust D, Caillaud J and Fontaine C 2006 Clay minerals in early amphibole weathering: Tri- to dioctahedral sequence as a function of crystallization sites in the amphibole; Clay Miner. 54 351-362.

$\mathrm{Pu} \mathrm{H}$, Xie X, Yin P and Morrow N 2010 Low salinity waterflooding and mineral dissolution; In: SPE Annual Technical Conference and Exhibition.

Rezaeidoust A, Puntervold T, Strand S and Austad T 2009 Smart water as wettability modifier in carbonate and sandstone: A discussion of similarities/differences in the chemical mechanisms; Energy Fuels 23 44794485 .

Ryder A G 2005 Analysis of crude petroleum oils using fluorescence spectroscopy; In: Reviews in Fluorescence (eds) Geddes C D and Lakowicz J R, Springer, USA, 2 169-198.

Saikia B J and Parthasarathy G 2010 Fourier transform infrared spectroscopic characterization of Kaolinite from Assam and Meghalaya, northeastern India; J. Mod. Phys. $1206-210$.

Sanyal S, Bhui U K, Kumar S S and Balaga D 2017 Designing injection water for enhancing oil recovery from Kaolinite Laden hydrocarbon reservoirs: A spectroscopic approach for understanding molecular level interaction during saline water flooding; Energy Fuels 31 11,627-11,639.

Sheng J J 2014 Critical review of low-salinity waterflooding; J. Pet. Sci. Eng. 120 216-224.

Shi Q, Hou D, Chung K H, Xu C, Zhao S and Zhang Y 2010 Characterization of Heteroatom compounds in a crude oil and its saturates, aromatics, resins, and asphaltenes (SARA) and non-basic nitrogen fractions analyzed by negative-ion electrospray ionization Fourier transform ion cyclotron resonance mass spectrometry; Energy Fuels 20 2545-2553.

Sugahara Y, Satokawa S, Kuroda K and Kato C 1990 Preparation of a kaolinite-polyacrylamide intercalation compound; Clay Miner. 38 137-143.

Tang G Q and Morrow N R 1999 Influence of brine composition and fines migration on crude oil/brine/rock interactions and oil recovery; J. Pet. Sci. Eng. 2499 111.

Tyagi B, Chudasama C D and Jasra R V 2006 Determination of structural modification in acid activated montmorillonite clay by FT-IR spectroscopy; Spectrochim. Acta A 64 273-278.

Underwood T, Erastova V, Cubillas P and Greenwell H C 2015 Molecular dynamic simulations of montmorilloniteorganic interactions under varying salinity: An insight into enhanced oil recovery; J. Phys. Chem. 119 7282-7294.

Velde B and Meunier A 2008 Clay mineral formation in weathered rocks: Water/rock interaction; In: The Origin of Clay Minerals in Soils and Weathered Rocks, Springer, Berlin, Heidelberg, pp. 143-239.

Worasith N, Goodman B A, Neampan J and Jeyachoke N 2011 Characterization of modified kaolin from the Ranong deposit Thailand by XRD, XRF, SEM, FTIR and EPR techniques; Clay Miner. 46 539-559. 
Worden R H and Morad S 2003 Clay minerals in sandstones: Controls on formation; Int. Assoc. Sedimentol. Spec. Publ. $343-41$.

Xie Q, Liu Y, Wu J and Liu Q 2014 Ions tuning water flooding experiments and interpretation by thermodynamics of wettability; J. Pet. Sci. Eng. 124350 358.

Yoon S, Bhatt S D, Lee W, Lee H Y, Jeong S Y, Baeg J and Lee C W 2009 Separation and characterization of bitumen from Athabasca oil sand; Korean J. Chem. Eng. 26 64-71.

Corresponding editor: PARTha Pratim Chakraborty
Yousef A A, Al-saleh S, Al-kaabi A, Al-jawfi M and Aramco S 2010 Laboratory investigation of novel oil recovery method for carbonate reservoirs; In: Canadian Unconventional Resources $\&$ International Petroleum Conferences.

Zhang P and Austad T 2006 Wettability and oil recovery from carbonates: Effects of temperature and potential determining ions; Colloids Surf. A 279 179-187.

Zhao X, Wang Y, Ye Z, Borthwick A G L and Ni J 2006 Oil field wastewater treatment in biological aerated filter by immobilized microorganisms; Process Biochem. 41 1475-1483. 